\title{
Conversação e deliberação sobre questões sensíveis: um estudo sobre o uso das razões que circulam nos media
}

\author{
Rousiley C. M. Maia \\ Danila Cal \\ Gabriella Hauber \\ Vanessa V. de Oliveira \\ Patrícia G. C. Rossini \\ Rafael C. Sampaio \\ Regiane Lucas Garcês
}

Resumo: A discussão informal tem despertado crescente interesse em estudos sobre deliberação. Contudo, são raros os estudos que examinam o engajamento das pessoas em contextos conflitantes. Este artigo investiga o modo pelo qual sujeitos de grupos sociais em conflito fazem uso de razões concorrentes que circulam nos media para negociar suas opiniões sobre uma "questão sensível": a redução da maioridade penal. Para tanto, foram realizados cinco grupos de discussão em Belém (PA) e Belo Horizonte (MG), com policiais militares e moradores e adolescentes de periferia. A partir da adaptação do Discourse Quality Index, este estudo analisa: as justificativas expressas pelos participantes; o respeito entre os grupos; o papel das histórias pessoais na discussão. Investiga-se, ainda, o fluxo de argumentos antes e após a apresentação do material dos media. Os resultados contribuem para compreender a dinâmica através da qual os sujeitos se situam num "espaço de razões" em debates plurais.

Palavras-Chave: deliberação; conflito social; conversação informal; maioridade penal.

Abstract: Conversation and deliberation across sensitive issues: a study on the use of media arguments on interpersonal debates - Informal debates have attracted increasing attention in deliberation studies. However, studies that explore how people make sense of plural information in the media are rare. This paper analyses how subjects from antagonizing social groups engage with a variety of media arguments to negotiate their opinions on a sensitive issue: the reduction of the criminal responsibility age in Brazil. We conducted five discussion groups in Belem (PA) and Belo Horizonte (MG) with members of the local police and with teenagers and 
adults who live in marginalized communities. By using an adapted version of the Discourse Quality Index, this study analyses: the justifications expressed during the discussion, the respect between groups and the role of personal stories in debates. It also investigates the arguments flow before and after the exposition of the media material to participants. The results contribute for advancing the understanding of the dynamics by which subjects situate themselves in a "space of reasons" in plural debates.

Keywords: deliberation; conflict; informal conversation; criminal responsibility age.

Este estudo investiga como grupos de cidadãos debatem uma "questão sensível" a participação de adolescentes em atos infracionais e a redução da maioridade penal e como se engajam com argumentos "publicamente disponíveis" (HABERMAS, 2006) que circulam no sistema híbrido dos media (CHADWICK, 2013). A conversação cotidiana e a discussão informal têm despertado crescente interesse em estudos sobre deliberação (CONOVER; SEARING, 2005; MARQUES; MAIA, 2010; MOY; GASTIL, 2006; WRIGHT, 2012; STEINER, JARAMILLO, MAIA; MAMELI, 2016). Contudo, ainda são raros os estudos que examinam o modo pelo qual os argumentos que circulam nos media incidem sobre processos concretos de debate. Esta investigação é relevante porque a comunicação que ocorre através dos media é uma parte intrínseca à conversação política (GAMSON 1992; MAIA 2012; MOY; GASTIL, 2006; KIM; KIM, 2008).

Sustentamos que as pessoas estão sempre expostas a um "espaço de razões" na vida cotidiana em sociedades pluralistas (HABERMAS, 2006, p.139; HONNETH, 2002, p.507), mas a oportunidade de trocar opiniões com sujeitos que possuem perspectivas divergentes não é frequente nas relações face-a-face. Para entender como grupos de pessoas concernidas se expressam sobre a proposta de redução penal, conduzimos cinco grupos de discussão em Belém (PA) e Belo Horizonte (MG) - compostos por moradores e adolescentes de periferia e policiais militares. Nesta pesquisa, seguimos a definição de Mark Warren segundo a qual uma questão é "sensível" quando há, entre os interlocutores, "histórias de exclusão, opressão, discriminação ou violência" (WARREN, 2006, p.170). Os participantes nos grupos de discussão foram incentivados a discutir espontaneamente sobre o tema e, posteriormente, expostos a argumentos concorrentes que circulam nos media acerca da redução da maioridade penal.

Em nossa análise, enfatizamos: (a) as justificativas mobilizadas para sustentar as opiniões; (b) o tipo de apelo (bem comum, princípios abstratos) dos argumentos; (c) a relação entre os grupos e (d) o papel das histórias pessoais na discussão. Investigamos, ainda, o fluxo de argumentos antes e após a apresentação do material dos media. Este artigo está assim estruturado: na primeira seção, discutimos as interfaces entre deliberação e conversação, promovendo uma articulação com sistema dos media. Explicamos o desenho da pesquisa e os procedimentos metodológicos na segunda seção. Na terceira, apresentamos os resultados e, na quarta, a análise. A última seção traz as conclusões desta pesquisa. 


\section{Deliberação e conversação informal: interações num "espaço de razões"}

O crescente interesse de estudos sobre deliberação em discussões informais pode ser brevemente explicado a partir de três eixos principais. Primeiro, as conversações podem ser entendidas como "pré-requisitos" (CONOVER; SEARING, 2005; ZANG; CHANG, 2014) para a deliberação formal. No dia a dia, indivíduos aprendem a articular e a defender suas visões; a identificar e a compreender questões de interesse público (MANSBRIDGE, 1999) e a definir o pertencimento e o desengajamento a grupos (BENHABIB, 2002). Isso representa uma condição necessária (mas insuficiente) para que as pessoas se tornem autônomas. Segundo, as conversações informais podem ser vistas como ensaios para debates mais estruturados, que seguem mais de perto os exigentes critérios da deliberação (CONOVER; SEARING, 2005; MANSBRIDGE 1999; PARKINSON et al., 2012). Em círculos de pessoas conhecidas, os sujeitos examinam seus argumentos, negociam interesses ou desacordos morais com os outros e praticam a razão pública. Conquistam, assim, capacidades deliberativas e recursos para se engajar em debates estruturados. Terceiro, as conversações informais sobre temas políticos ajudam a aperfeiçoar o conhecimento político (CONOVER; SEARING, 2005; WALSH, 2004), a refinar opiniões e aumentar a eficácia política (JACOBS; COOK; DELLI CARPINI, 2009; MOY; GASTIL, 2006). Essas práticas estabelecem um "intercâmbio" constante com debates mais amplos que ocorrem em fóruns formais e servem de pano de fundo para avaliar decisões políticas. No entanto, a conversação informal não é sempre benéfica para a democracia, uma vez que ela pode destinar-se à coerção, à intolerância, e às mais diversas formas de dominação. Por essas razões, os critérios deliberativos contribuem para avaliar o potencial democrático desse tipo de discussão.

Nesse estudo, partimos da premissa de que distintos tipos de media, por meio de complexos processos de mediação e construção de visibilidades, desempenham um papel importante na constituição e reconstituição do "espaço de razões" na sociedade. Entendemos essa dinâmica como circular. Isso porque os profissionais dos media, "[não] formulam novos argumentos ou articulam razões inteiramente por si próprios", como destaca Mutz (2006, p.149). Ao invés disso, "mesmo aqueles comentaristas que argumentam como 'profissionais' estão, na maioria das vezes, rearticulando argumentos políticos pré-existentes" (MUTZ, 2006, p.149). Questões controversas - debatidas em casas parlamentares, em fóruns de entidades de classe, reuniões científicas, encontros de movimentos sociais etc. - circulam pelo sistema híbrido dos media e se tornam temas de conversas face a face ou via Internet e redes sociais. Sob certas condições, essa "conversação da sociedade com ela mesma" (BRAGA, 2006) serve de "contexto discursivo" (BÄCHTINGER et al., 2010). As pessoas recorrem a imagens, narrativas factuais e ficcionais, discursos e argumentos que circulam no sistema híbrido dos media como "recursos conversacionais" (GAMSON, 1992). Diante desse cenário, cabe indagar: como as pessoas "se situam" nesse espaço de razões? A partir de um debate específico - 
a redução da maioridade penal - como elas interagem com os argumentos que circulam nos media ao justificar suas posições e expressar suas experiências pessoais? De que modo elas negociam seus entendimentos em um contexto de conversação plural?

\section{Negociando as razões que circulam nos media}

A exposição a visões políticas distintas é valorizada como uma prática positiva para a democracia (HUCKFELDT; JOHNSON; SPRAGUE, 2004; MUTZ, 2006). Estudos convencionais sobre efeitos dos media tendem a examinar os usos de media pelos sujeitos e as suas fontes de informação política. Essa tarefa mostra-se cada vez mais complicada num ambiente interconectado de media. Isso porque um sistema interdependente de relações é estabelecido entre diferentes tipos de media e plataformas ( $T V$, jornais, revistas, sites na Internet e redes sociais online), o qual potencialmente inclui diferentes modalidades de comunicação (CHADWICK, 2013). As pessoas circulam e modificam os conteúdos dos media e aqueles dos próprios usuários, através da Internet e das redes sociais, frequentemente de maneira colaborativa. Ademais, no sistema interconectado de media, há maiores chances de "exposição inadvertida" a conteúdos dissonantes, mesmo quando os sujeitos não procuram por tais informações (BRUNDIDGE, 2010). Assim, detectar efeitos específicos de determinado tipo de media ou de programa mediático torna-se uma tarefa extremamente complexa.

São recorrentes, nesse contexto, pesquisas sobre enquadramento nas quais as pessoas são expostas a uma única interpretação (frame). Mais raros são estudos sobre enquadramentos concorrentes (competing frames) (CHONG; DRUCKMAN, 2007; SNIDERMAN ; THERIAULT, 2004). Nossa investigação busca captar uma imagem da atividade social da argumentação em um contexto de razões concorrentes. Esta proposta se distingue de estudos sobre enquadramento de duas maneiras. Nesses estudos as pessoas são expostas a interpretações diferentes sobre uma dada questão e, tipicamente, reportam suas opiniões individuais (CHONG; DRUCKMAN, 2007; SNIDERMAN; THERIAULT, 2004). Em nosso estudo, os participantes foram expostos a diversos argumentos a favor e contra o tema em tela, como recursos conversacionais (GAMSON, 1992). Assumimos que os participantes expressariam entendimentos e sentimentos aos demais, cujas demandas ficariam sujeitas ao reforço, ao confronto, ou à alteração dentro do grupo. Segundo, distintamente de estudos que buscam aferir a "saliência" de enquadramentos na opinião pública e que, para tanto, as pessoas enumeram a persuasão de uma mensagem ou de um enquadramento (CHONG; DRUCKMAN, 2007; SNIDERMAN; THERIAULT, 2004), esta pesquisa utiliza métodos mistos para apreender o fenômeno. Primeiro, analisamos questionários aplicados no início e ao fim da discussão e, segundo, utilizamos a metodologia de análise de conteúdo para avaliar a prática concreta de debate antes e depois da exposição dos participantes aos argumentos dos media. 


\section{Caso: A proposta de redução da maioridade penal}

A legislação brasileira estabelece a maioridade penal aos 18 anos. Antes dessa idade, os adolescentes entre 12 a 17 anos que praticarem um ato infracional são encaminhados para o chamado sistema socioeducativo. De acordo com a gravidade do ato, as medidas socioeducativas previstas pelo Estatuto da Criança e do Adolescente (ECA) vão desde a obrigação de reparar o dano até a internação nessas instituições.

A idade penal aos 18 anos é um tema altamente controverso, desde a promulgação do ECA. Uma pesquisa divulgada em junho de 2013 pela Confederação Nacional dos Transportes revelou que 92,7\% dos brasileiros são a favor da redução da maioridade penal de 18 anos para 16 anos. No período de realização dos grupos de discussão dessa pesquisa (entre outubro e novembro de 2014), a Proposta de Emenda Constitucional $N^{\circ}$ 33, de 2012 (PEC 33/2012), gerou grande polêmica. Ela visa alterar a Constituição Federal, de 1988, e o ECA, ao propor a redução da maioridade penal dos 18 para os 16 anos, no caso de "crimes" de alta gravidade, como homicídio qualificado e estupro.

\section{Procedimentos Metodológicos}

Quando os cidadãos são expostos a perspectivas que reforçam suas predileções, a oportunidade de considerar pontos de vistas alternativos diminui e o potencial para uma "conversa deliberativa" é reduzido. Por essa razão, optamos por observar como pessoas de grupos conflitantes interagem ao debater questões sensíveis ao contexto em que vivem: a proposta de redução da maioridade penal. Para tanto, realizamos cinco grupos de discussão - dois em Belo Horizonte e três em Belém, com a participação de moradores de comunidades periféricas, adultos e adolescentes, e integrantes da Polícia Militar.

Para identificação dos participantes e organização dos grupos, contamos com o apoio dos projetos sociais Rede Escola Cidadã (Belém) e Fica Vivo (BH), de lideranças comunitárias e das Polícias Militares estaduais. No total, 60 pessoas participaram sendo que a quantidade mínima nos grupos foi de 10 e máxima de 17.

Os grupos de discussão tiveram duração aproximada de duas horas e meia. Num primeiro momento, os participantes discutiram questões relacionadas ao conflito social entre policiais e moradores de bairros de periferia e, em seguida, a redução da maioridade penal. Esta etapa do debate teve duração aproximada de uma hora. Para iniciar o debate, as moderadoras perguntaram: Qual sua opinião sobre a proposta de lei para redução da maioridade penal? O que deve ser feito? Após uma discussão inicial por 30 minutos, foi apresentado um vídeo produzido para a pesquisa que exibia, de modo intercalado, oito argumentos contra e oito argumentos a favor da redução, extraídos de fontes como telejornais e reportagens de TV, audiências públicas (televisionadas), páginas do Facebook, jornais e revistas. 
Ao início e no final das discussões, foram aplicados questionários para caracterizar os participantes e aferir seus posicionamentos. Os questionários apresentaram 15 afirmativas relacionadas ao tema para que os participantes indicassem sua posição, dentro de uma escala Likert (1932) de sete pontos: "concordo inteiramente", "concordo", "eu não concordo, nem discordo", "não tenho opinião formada", "discordo", "discordo inteiramente" e "não sei". Além disso, havia uma questão direta sobre o posicionamento do participante nos dois questionários. O participante deveria escolher entre as opções: "a favor da redução"; "contra a redução"; "neutro/balanceado"; "não sabe".

Os grupos de discussão tiveram apenas o áudio gravado para garantir a segurança dos participantes. Posteriormente, as falas foram transcritas para a condução da análise de conteúdo (KRIPPENDORF, 2003; NEUENDORF, 2008). O livro de códigos foi elaborado a partir de uma adaptação do Discourse Quality Index (DQI), em sua última versão (STEINER, 2012), e a unidade de análise foi o proferimento ${ }^{1}$. No total, foram codificados 201 proferimentos em 12 códigos $^{2}$. Para os propósitos deste trabalho, enfatizamos as seguintes variáveis: respeito (dividido em: uso de linguagem chula, uso de linguagem respeitosa e escuta respeitosa); nível de justificação dos argumentos; conteúdo da justificação dos argumentos (dividido em: próprio grupo, outro grupo, bem comum e princípios abstratos); força do melhor argumento; histórias.

De modo qualitativo, identificamos ainda os argumentos mobilizados antes e após a exibição do vídeo. Para isso, construímos uma lista com 18 argumentos disponíveis publicamente sobre a redução da maioridade penal, inclusive os que apareciam no vídeo apresentado. Consideramos que um proferimento poderia não conter argumentos ou conter mais de um argumento. Nesta análise encontramos 151 ocorrências de argumentos.

\section{Resultados}

O posicionamento dos participantes a respeito da redução da maioridade penal, registrado por meio do questionário inicial, revelou significativa heterogeneidade. Houve divergência de posturas favoráveis e contrárias à redução penal, distribuídas de modo semelhante entre as categorias de participantes. Entre aqueles que expressaram uma posição (i.e, eliminando-se os que se declaram neutros ou não responderam), há mais participantes a favor da redução da maioridade penal, distribuída nas seguintes proporções: policiais $(47,7 \%)$, moradores de periferia (47\%) e adolescentes $(40,9 \%)$.

No que tange à intensidade da adesão a certos argumentos, os dados mostram que há relativa homogeneidade com relação às razões que motivam os participantes a assumir seus posicionamentos. A Tabela 1 mostra que os argumentos que tiveram maior

1 A análise de conteúdo foi conduzida por duas codificadoras, que passaram por sessões de treinamento até atingir percentuais de concordância desejáveis.

2 Por limites de espaço, as variáveis foram suprimidas. O livro de códigos poderá ser disponibilizado mediante pedido aos autores, através do seguinte e-mail: rousiley@fafich.ufmg.br 
adesão ("concordo" + "concordo inteiramente") e maior rejeição ("discordo" + "discordo inteiramente") são semelhantes em todas as categorias antes dos grupos de discussão.

\begin{tabular}{l|ll}
$\begin{array}{l}\text { Categoria de } \\
\text { Partic ipante }\end{array}$ & Argumento de maior ad esão & Argumento de maior rejeiç ão \\
\hline Polic iais & $\begin{array}{l}\text { Atos infracionais cometidos por } \\
\text { adolescentes estão aumentando } \\
(94.70 \%)\end{array}$ & $\begin{array}{l}\text { As medidas socioeducativas } \\
\text { aplica das a adolescentes que } \\
\text { cometem atos infiacionais são } \\
\text { suficientes enquanto forma de } \\
\text { responsabiliza cão } \\
(78.90 \%)\end{array}$ \\
$\begin{array}{l}\text { Moradores } \\
\text { de Periferia }\end{array}$ & $\begin{array}{l}\text { Atos infracionais cometidos por } \\
\text { adolescentes estão aumentando; e Os } \\
\text { adolescentes de classe média e classe al ta } \\
\text { que cometem atos infracionais não } \\
\text { costumam ser responsabilizados como os } \\
\text { de classes mais baix as } \\
(94.10 \%)\end{array}$ & $\begin{array}{l}\text { As medidas socioeducativas } \\
\text { aplicadas a adolescentes que } \\
\text { cometem atos infracionais são } \\
\text { suficientes enquanto forma de } \\
\text { responsabiliza cão } \\
(73.60 \%)\end{array}$ \\
\hline $\begin{array}{l}\text { Adolescentes } \\
\text { de periferia }\end{array}$ & $\begin{array}{l}\text { Atos infracionais cometidos por } \\
\text { adolescentes estão aumentando } \\
(86.30 \%)\end{array}$ & $\begin{array}{l}\text { As medidas socioeducativas } \\
\text { aplicadas a adolescentes que } \\
\text { cometem atos infiacionais são } \\
\text { suficientes enquanto forma de } \\
\text { responsabilização } \\
(73.60 \%)\end{array}$ \\
\hline
\end{tabular}

Tab. 1. Afirmações com maior adesão e rejeição por categoria de participante antes dos grupos de discussão Fonte: Grupo EME-UFMG

A Tabela 2 mostra as afirmações que contavam com maior adesão antes da discussão, registradas por meio do questionário, considerando o total de participantes.

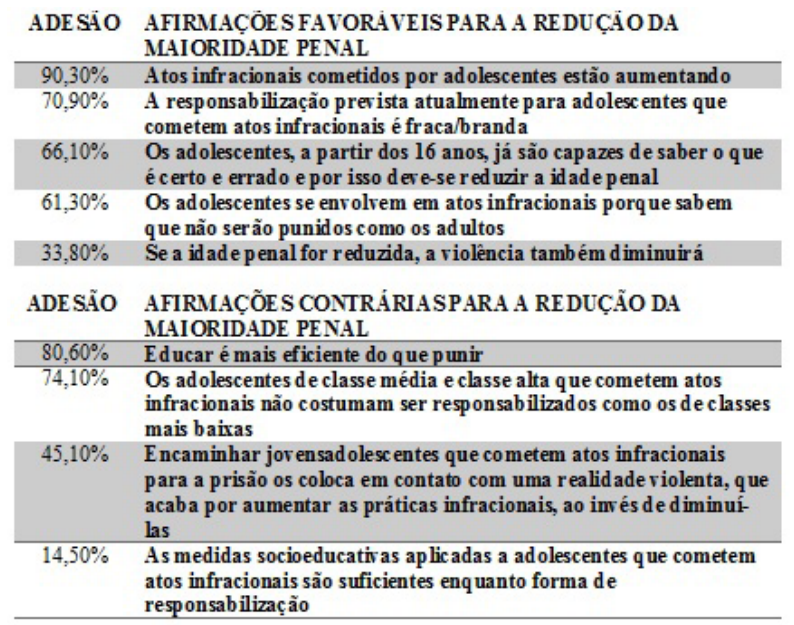

Tab. 2. Afirmações com maior adesão antes dos grupos de discussão Fonte: Grupo EME-UFMG

No tocante aos elementos deliberativos da discussão, observamos as variáveis supracitadas em dois momentos: (i) antes e (ii) após a exposição do vídeo. Não houve 
diferença significativa na maioria das variáveis nesses dois momentos. A Figura 1 mostra que a porcentagem de argumentos que se referiam ao bem comum permaneceu semelhante. Já os argumentos que apelavam para princípios abstratos tiveram um aumento considerável após a exibição do material.

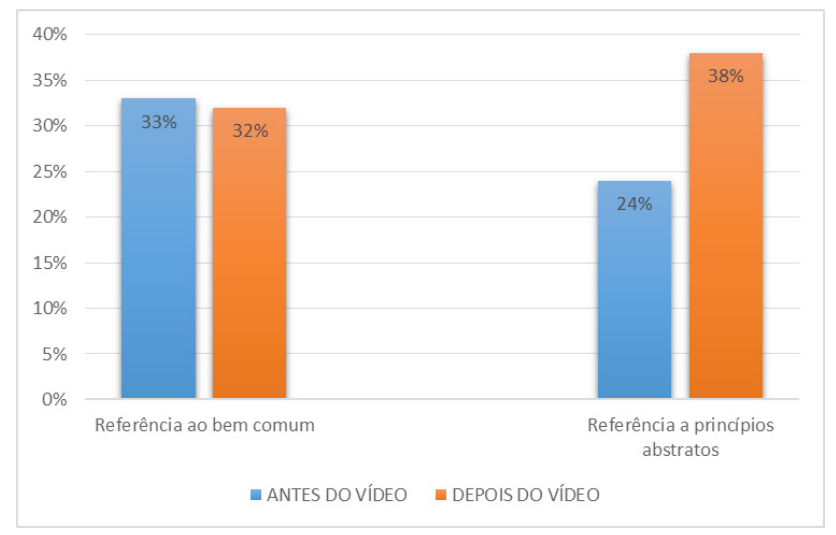

Fig. 1. Referência ao bem comum e a princípios abstratos antes e após o vídeo. Fonte: Grupo EME-UFMG

A Figura 2 mostra que os argumentos que faziam referência ao próprio grupo tiveram um ligeiro aumento após a exposição do vídeo, enquanto a referência ao outro grupo permaneceu constante.

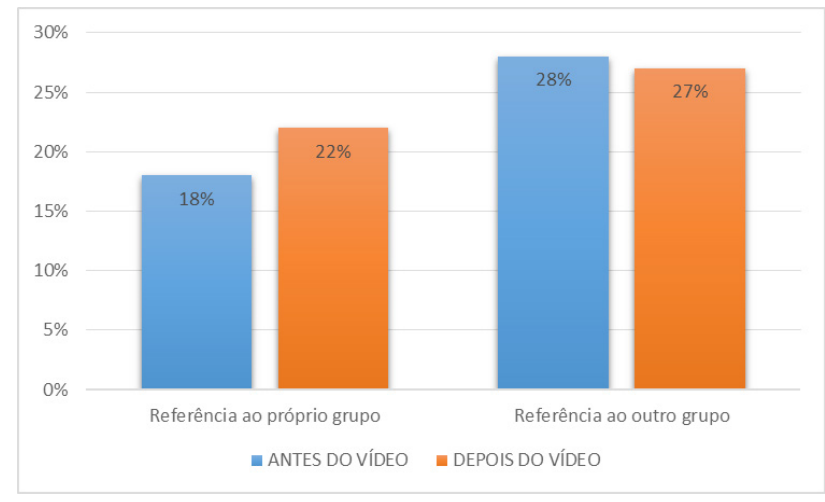

Fig. 2. Referência ao próprio grupo e ao outro grupo antes e após o vídeo. Fonte: Grupo EME-UFMG

A Figura 3 mostra que cerca de 20\% dos argumentos estavam ligados a histórias pessoais. Também nesse caso, a exibição dos argumentos que circulam nos media não alterou a motivação dos participantes em expressar um número maior ou menor de histórias 
pessoais durante o debate. Nota-se, contudo, que houve, após o vídeo, um pequeno aumento das histórias complexas, em detrimento das histórias simples (BLACK, 2008; ADAMS, 2014), i.e., aquelas que fazem referência às experiências pessoais in passim.

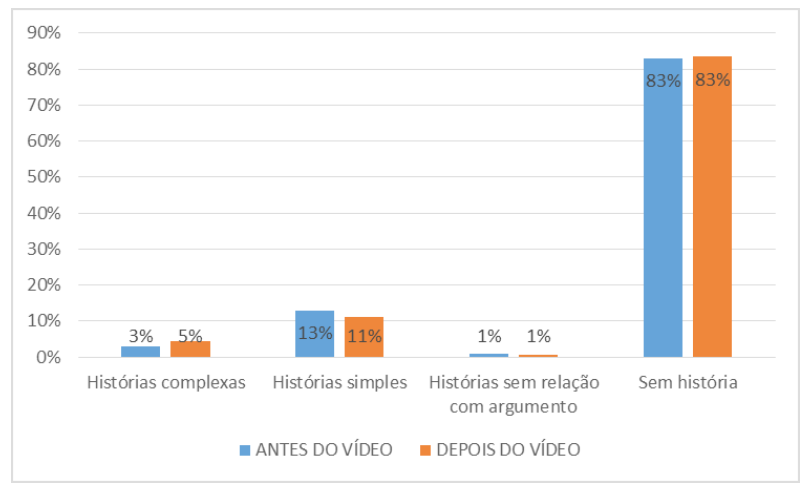

Fig. 3. Uso de histórias pessoais. Fonte: Grupo EME-UFMG

Os dados mostram ainda que, durante o processo de discussão inicial, não foi possível detectar reversibilidade das opiniões, isto é, expressões em que as pessoas explicitamente revelam que mudaram de opinião ou de preferência. A Figura 4 mostra que, após o vídeo, $10 \%$ dos participantes reconhecem alteração na posição, sendo que 3\% reconhecem o argumento do outro como causa da mudança.

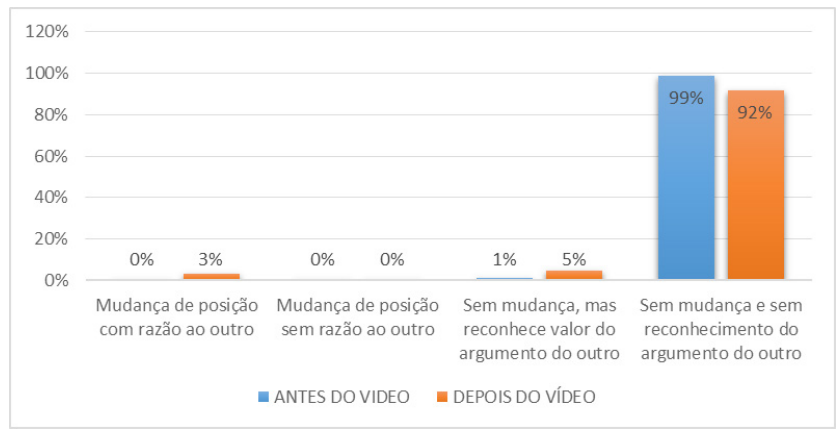

Fig. 4. Revisibilidade de posição em razão do argumento do outro. Fonte: Grupo EME-UFMG

Em relação aos níveis de justificação dos argumentos, detectamos, contudo, uma alteração significativa. Como mostra a Figura 5, após a exposição das razões que circulam nos media, os participantes passaram a expressar suas posições com um volume maior de justificativas. Por sua vez, o número de proferimentos sem qualquer argumento reduz sensivelmente. 


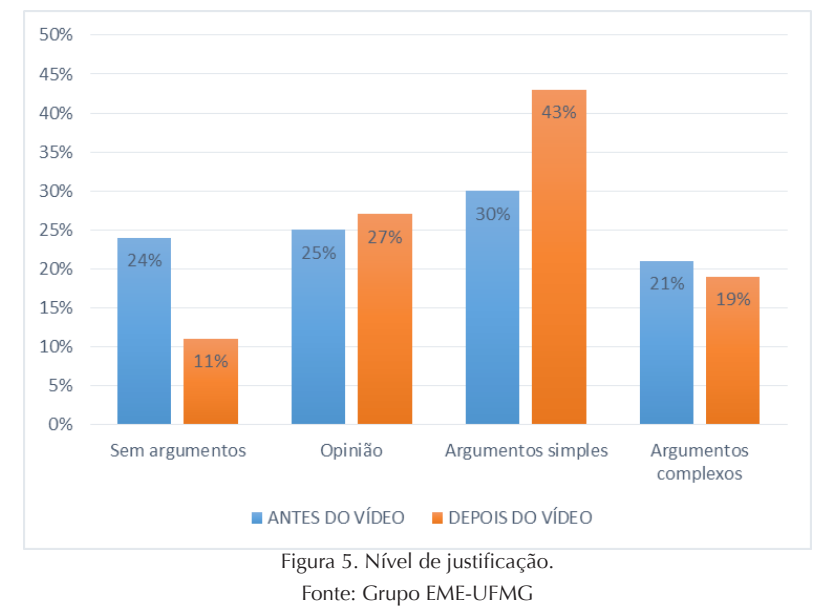

A fim de compreender esses resultados com maior acuidade, realizamos um estudo qualitativo das razões que foram mobilizadas nos dois momentos da discussão. A figura 6 apresenta a frequência de cada argumento antes e após a exibição das razões que circulam nos media. Logo após, a tabela 3 descreve a lista de argumentos cuja dinâmica observamos na figura 6 .

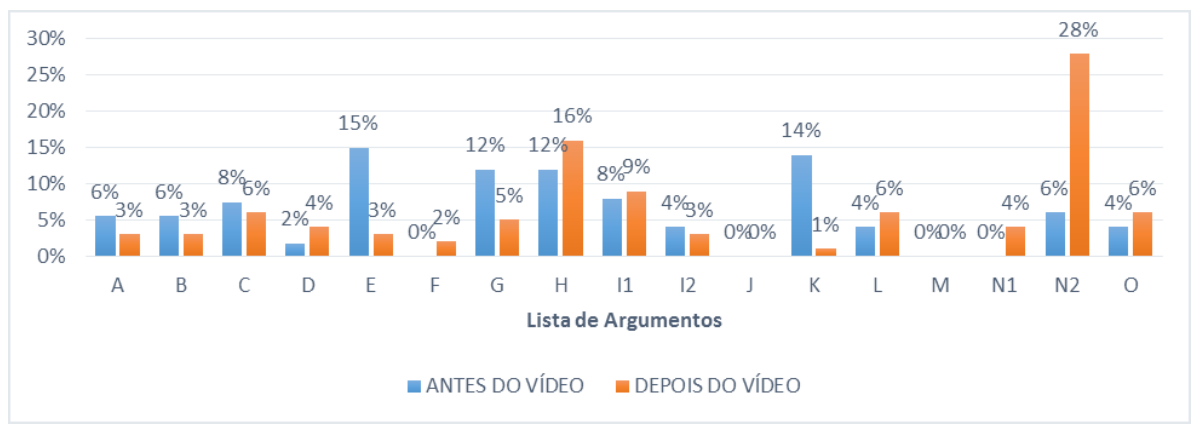

Fig. 6. Dinâmica dos argumentos antes e após o vídeo Fonte: Grupo EME-UFMG 
ARGUMENTOS A FAVOR DA REDUÇÃO DA MAIORIDADE PENAL

\begin{tabular}{c|l}
\hline $\begin{array}{c}\text { ARGUMENT } \\
\text { O }\end{array}$ & \multicolumn{1}{c}{ DESCRIÇÃO } \\
\hline A & $\begin{array}{l}\text { O número de atos infracionais cometidos por adolescentes está aumentando, por } \\
\text { isso é preciso que eles respondam criminalmente, o que resultará na diminuição da } \\
\text { violência }\end{array}$ \\
\hline B & $\begin{array}{l}\text { A responsabilização prevista atualmente para adolescentes que cometem atos } \\
\text { infracionais graves é fraca/branda porque o ECA não é adequado à realidade atual } \\
\text { e, por isso, é preciso reduzir a maioridade penal }\end{array}$ \\
\hline C & $\begin{array}{l}\text { Os adolescentes, a partir dos 16 anos, já são capazes de saber o que é certo e errado } \\
\text { e, por isso, deve-se reduzir a idade penal }\end{array}$ \\
\hline D & $\begin{array}{l}\text { Se os adolescentes aos 16 anos os têm inúmeros direitos, eles devem responder } \\
\text { criminalmente por seus atos infracionais. Em vários paises a idade penal é abaixo } \\
\text { dos 18 anos }\end{array}$ \\
\hline E & Os adolescentes se envolvem em atos infracionais porque sabem da impunidade \\
\hline F & $\begin{array}{l}\text { A redução da maioridade tem amplo apoio popular e reduzir a idade penal satisfaz } \\
\text { a vontade da maioria. }\end{array}$ \\
\hline G & $\begin{array}{l}\text { Deve haver redução da maioridade penal, mas politicas públicas precisam ser } \\
\text { desenvolvidas para aperfeiçoar o sistema carcerário para receber adolescentes }\end{array}$ \\
\hline
\end{tabular}

ARGUMENTOS CONTRÁRIOS À REDUÇÃO DA MAIORIDADE PENAL

\begin{tabular}{c|l}
\hline $\begin{array}{c}\text { ARGUMENT } \\
\text { O }\end{array}$ & \multicolumn{1}{c}{ DESCRIÇÃO } \\
\hline H & $\begin{array}{l}\text { Educar é mais eficiente do que punir, sendo mais eficaz investir em politicas } \\
\text { públicas para evitar que adolescentes se envolvam em atos infracionais }\end{array}$ \\
\hline I1 & $\begin{array}{l}\text { Encaminhar adolescentes que cometem atos infracionais para a prisão os coloca em } \\
\text { contato com uma realidade violenta, que acaba por aumentar as práticas } \\
\text { infracionais, ao invés de diminui-las. }\end{array}$ \\
\hline I2 & $\begin{array}{l}\text { Encaminhar adolescentes que cometem atos infracionais para a prisão irá } \\
\text { complicar ainda mais o sistema carcerário que está superlotado }\end{array}$ \\
\hline K & $\begin{array}{l}\text { A maioria dos atos infracionais é de menor gravidade e, por, isso reduzir a idade } \\
\text { penal não resolverá o problema da violência }\end{array}$ \\
\hline L & $\begin{array}{l}\text { Grupos criminosos irão cooptar crianças e adolescentes cada vez mais novos, caso } \\
\text { a maioridade penal seja reduzida. Por isso, reduzir a maioridade não soluciona o } \\
\text { problema da violência }\end{array}$ \\
\hline M & $\begin{array}{l}\text { Os adolescentes de classe baixa serão mais prejudicados porque os de classe média } \\
\text { e alta não costumam ser responsabilizados. A maioria dos adolescentes que } \\
\text { cometem atos infracionais vem de situações de pobreza e de familias } \\
\text { desestruturadas. É um problema social, não de criminalidade }\end{array}$ \\
\hline N1 & A maioridade penal aos 18 anos é cláusula pétrea. É um compromisso internacional \\
\hline N2 & $\begin{array}{l}\text { As medidas socioeducativas aplicadas a adolescentes que cometem atos } \\
\text { infracionais são suficientes enquanto forma de responsabilização, portanto, basta } \\
\text { cumprir a lei; }\end{array}$ \\
\hline $\begin{array}{l}\text { As medidas socioeducativas aplicadas a adolescentes que cometem atos } \\
\text { infracionais são suficientes enquanto forma de responsabilização, mas é preciso } \\
\text { corrigir e aperfeiçoar o sistema socioeducativo }\end{array}$ \\
\hline $\begin{array}{l}\text { Adolescentes são sujeitos em condição de desenvolvimento e, portanto, não se } \\
\text { deve reduzir a maioridade penal }\end{array}$ \\
\hline
\end{tabular}

Tab. 3. Lista de argumentos

Fonte: Grupo EME-UFMG

O resultado do fluxo de argumentos apresenta dois achados relevantes. O primeiro diz respeito à pluralização dos argumentos mobilizados nos grupos. Após tomarem contato com as razões que circulam nos media, os participantes passam a utilizar uma variedade maior de tipos distintos de argumentos. O segundo achado refere-se à natureza 
dos argumentos utilizados. Com o desenrolar da conversa e após a exibição dos argumentos dos media, os participantes passam a acionar argumentos contrários à redução penal com mais frequência. A Tabela 4 mostra a mudança na qualidade substantiva dos argumentos.

\begin{tabular}{c|c|c|c}
$\begin{array}{c}\text { ARGUMENTOS } \\
\text { ANTES DO VÍDEO }\end{array}$ & $\%$ & $\begin{array}{c}\text { ARGUMENTOS APÓS } \\
\text { VÍDEO }\end{array}$ & $\%$ \\
\hline $\mathrm{E}$ & $15 \%$ & $\mathrm{~N} 2$ & $28 \%$ \\
\hline $\mathrm{K}$ & $14 \%$ & $\mathrm{H}$ & $16 \%$ \\
\hline $\mathrm{G}$ & $12 \%$ & $\mathrm{l}-1$ & $9 \%$ \\
\hline $\mathrm{H}$ & $12 \%$ & &
\end{tabular}

Tab. 4. Lista dos argumentos mais mobilizados pelo total de participantes antes e após a exibição do vídeo Fonte: Grupo EME-UFMG

Estes dados são coerentes com a declaração dos participantes sobre a mudança do próprio posicionamento, registrada nos questionários finais. Esses questionários revelam que houve uma diminuição de participantes favoráveis à redução da maioridade penal em todas as categorias: Policiais (47,3\% antes vs 36,8\% depois); Moradores de periferia (47\% vs 35,3\%); Adolescentes (40,9\% vs 18,2\%). Por consequência, o número de participantes contrários à redução aumentou de modo consistente: Policiais (36,8\% antes vs 42,1\% depois); Moradores de periferia (23,5\% vs 35,5\%); Adolescentes (22,7\% vs 40,9\%). O número de participantes que assumiram uma posição neutra permaneceu constante na categoria de Policiais (15,8\% antes e depois) e de Moradores de periferia (29,4\% antes e depois). Houve, contudo, um pequeno aumento deste posicionamento entre os Adolescentes (31,8\% antes e 36,3\% depois).

\section{Discussão}

Neste estudo buscamos construir um contexto de debate marcado por considerações conflitantes acerca de um tema controverso. Em nossos grupos de discussão o nível de desacordo foi substancial. Houve considerável diferença de visões acerca da redução da maioridade penal dentre e entre as categorias de policiais, de moradores e adolescentes de periferia, o que indica que o pertencimento a um grupo não determina o posicionamento pessoal. Não obstante, as pessoas favoráveis à redução da idade penal foram maioria, numa proporção semelhante (oscilando entre 41\% e 47\%) nas distintas categorias.

Pela opinião declarada no questionário observamos certos padrões de acordo. Houve consenso antes do experimento, entre todas as categorias de participantes, sobre o diagnóstico de que "os atos infracionais cometidos por adolescente estão aumentando" e também que "as medidas socioeducativas aplicadas a adolescentes que cometem atos infracionais são insuficientes enquanto forma de responsabilização". Essa percepção compartilhada oferece um "terreno comum", a partir do qual os participantes estabelecem suas diferenças. Contudo, essa percepção não define as relações que os sujeitos 
estabelecem entre si a partir daí. O "espaço de razões", como propõe Laden (2012, p.17), não é constituído por pontos separados, mas por proposições que se conectam por um conjunto de relações inferenciais.

Nos grupos de discussão os participantes, ao expressarem suas opiniões, precisaram simultaneamente se situar num "espaço de razões" social, o qual é público e compartilhado. Eles se engajaram numa troca de razões para defender se a redução da maioridade penal irá ou não diminuir a violência social e precisaram discernir o que constitui responsabilização do menor infrator em cada situação específica. Polêmicas se desdobraram sobre a natureza moral da punição e da educação, a qualidade das políticas públicas direcionadas aos adolescentes e as classes sociais que seriam verdadeiramente atingidas com a redução da idade penal. Nesse quadro, enquanto os participantes favoráveis à redução defendiam que novas medidas de políticas públicas deveriam ser tomadas para adequar o sistema carcerário para receber adolescentes em conflito com a lei, participantes contrários à redução defendiam o aprimoramento do sistema socioeducativo.

Situar-se num espaço de razões não quer dizer que cada pessoa sustente os mesmos pontos de vista (LADEN, 2012, p.17). A questão fundamental é saber como os sujeitos se relacionam uns com os outros e como percebem sua responsabilidade diante do tipo de interação que constroem com os demais nesse espaço de razões. Nossa análise quantitativa, desenvolvida através do DQI, revela que uma série de elementos da discussão não se alterou ao longo do debate. A exibição do material mediático não alterou o volume de proferimentos que faziam apelo ao bem comum ou o nível de respeito entre os participantes, não transformou a motivação dos participantes para aludir a outro grupo afetado e não modificou a disposição das pessoas em assumir explicitamente alguma mudança de preferência ou revelou que elas foram convencidas pela "força do melhor argumento".

Esses dados sugerem que os cidadãos atuam ativamente na aquisição da informação política e na seleção de razões que circulam nos media. Nossos resultados indicam que os participantes, após engajarem-se com as opiniões conflitantes de outros indivíduos e após a exibição do vídeo, aperfeiçoaram seus argumentos. Ao invés de simplesmente absorver a informação disponível, eles passaram a justificar, com maior frequência, suas preferências e seus julgamentos. Ao passo que o volume de justificativas aumentou, o volume de expressões sem qualquer argumento diminuiu. Cabe destacar que prevaleceu o nível de justificação simples - em que apenas uma razão é mobilizada. Essa característica é esperada em debates informais, situação em que as pessoas usualmente não demonstram os passos de suas reflexões por meio da conexão entre as premissas, evidências e conclusões. Ao invés disso, elas passam rapidamente para as conclusões, deixando lacunas a serem inferidas pelos demais (GOODIN, 2006; STEINER et al., 2004). Nossa análise quantitativa mostra ainda que alguns participantes passaram a descrever eventos relacionados a si próprios ou ao próprio grupo com maior frequência. Possivelmente, o contexto mais amplo de razões, demonstrando a complexidade moral da situação, criou um clima emocional propício para eles falarem de si na primeira pessoa. 
Nossos achados corroboram os modelos comunicacionais que sustentam que os indivíduos filtram seletivamente a informação para sustentar suas posições. Em particular, nossa análise qualitativa revelou que houve uma substantiva alteração na natureza dos argumentos que foram trazidos à discussão, após a troca argumentativa no grupo e a exibição do material mediático. Por exemplo, no primeiro momento da discussão, o quadro de razões apresentava concorrência entre a solução punitiva do encarceramento de adolescentes em conflito com a lei e a solução educativa e preventiva; a responsabilização dos adolescentes vista sob o ponto de vista pessoal e a responsabilização dos grupos de criminosos que induzem os adolescentes a praticarem infrações. No segundo momento da discussão, ganha relevância a disputa sobre como políticas educativas e de lazer podem ser mais eficazes para prevenir que os adolescentes "caiam no mundo da criminalidade" e que as falhas de centros de internação precisam ser corrigidas, a fim de aperfeiçoar o sistema socioeducativo. Ganha saliência o argumento de que encaminhar o adolescente ao sistema carcerário coloca-o numa "escola do crime" e, portanto, essa medida poderia trazer danos ainda maiores para a sociedade no futuro. Nesse caso, o embate move-se para o terreno das controvérsias acerca dos efeitos colaterais em longo prazo do encarceramento de adolescentes e das responsabilidades de agentes e instituições públicas. Este resultado parece explicar o uso mais elevado de justificativas baseadas em princípios abstratos após a exibição do vídeo.

Os achados evidenciam uma aparente contradição com relação à mudança das opiniões dos participantes. Enquanto os dados do DQI mostram que houve baixíssima reversibilidade de preferências, a comparação dos posicionamentos indicados nos questionários iniciais e finais revela que os participantes alteraram seus posicionamentos. A análise do fluxo de argumentos evidencia a transformação no quadro de razões trocadas nos dois momentos. Como indicado por estudos sobre deliberação, as pessoas tendem a se sentir constrangidas em admitir explicitamente, numa situação de debate, que modificaram suas posições ou que foram convencidas pelos argumentos de seus opositores. Preferem, ao invés disso, parecer firmes e resolutas (CHAMBERS, 2005; GODDIN, 2005; STEINER et al., 2004; STASAVAGE, 2007). Numa visão de conjunto, nosso estudo sugere que a exposição às considerações conflitantes e razões concorrentes não apenas ajuda aos cidadãos a esclarecer suas preferências, mas, também, a transformá-las.

\section{Conclusão}

Iniciamos este estudo com a afirmação de que a conversação informal encontra-se entremeada com a comunicação que circula no sistema híbrido dos media. Indagamos como policiais, adolescentes e moradores de periferia discutem uma questão sensível, a redução da maioridade penal. Num contexto de interpretações concorrentes, os participantes se situaram num espaço de razões para constituir e reconstituir os contornos de suas opiniões e negociar seus anseios, valores e interesses com os demais. 
Por diversas vezes, fizeram referência ao material mediático para desenvolver polêmicas e expressar suas experiências pessoais. Vários elementos da conversação relacionados à deliberação - respeito, referência ao bem comum, menção a outros grupos, reversibilidade - permaneceram inalterados. Contudo, os participantes, ao serem expostos ao quadro de razões conflitantes, passaram a operar com um conjunto mais plural de argumentos e a justificar suas posições com mais frequência.

Tais resultados enfatizam um dos principais benefícios da conversação informal em contextos heterogêneos - a saber, a circulação de razões e argumentos plurais e o respeito às opiniões divergentes. Ainda que a conversação esteja desvinculada, na maioria das vezes, de processos formais de tomada de decisão, ela representa uma atividade central e estruturante da vida cotidiana em sociedades plurais. É através das trocas discursivas informais que indivíduos aprendem a articular suas posições, a compreender as posições dos outros e a identificar problemas que são de interesse público. O ato de negociar posições diante daqueles que adotam perspectivas distintas e de justificar as opiniões pessoais prepara o indivíduo para outros processos de participação política. Em condições adequadas, esta prática promove ganhos epistêmicos como o refinamento das opiniões individuais e a tolerância a perspectivas divergentes.

Os media desempenham papel relevante neste processo. De modo geral, os resultados desta pesquisa sinalizam a importância de deslindar o modo complexo através do qual as pessoas recorrem às "razões publicadas", disponíveis no sistema dos media, para se engajar em debates, onde quer que eles ocorram. Por um lado, os dados quantitativos contribuem para a compreensão sistemática de diferentes dimensões da deliberação que acontece em contextos informais, o que demonstra a proficuidade desse método. Por outro lado, nossos resultados apontam a necessidade de articulá-lo com categorias mais qualitativas. Foi da relação entre os resultados do DQI e da análise qualitativa da dinâmica de fluxo de argumentos que extraímos nossos principais achados.

Rousiley Celi Moreira Maia é professora titular da UFMG; doutora em ciência política pela Universidade de Nottingham e coordenadora do EME da UFMG.

rousiley@fafich.ufmg.br

Danila Cal é professora da Universidade da Amazônia (Unama); doutora em Comunicação Social, e bolsista de Pós-Doutorado (CNPq) no EME/UFMG.

danila.cal@unama.br

Gabriella Hauber é doutoranda em Comunicação Social (UFMG) e pesquisadora do Grupo EME/UFMG.

gabihauber@gmail.com 
Vanessa Veiga de Oliveira é doutoranda em Comunicação Social (UFMG); bolsista CAPES e pesquisadora do mesmo grupo.

veiga.jornalismo@gmail.com

Patrícia Gonçalves Conceição Rossini é doutoranda em Comunicação Social (UFMG); bolsista CAPES e pesquisadora do mesmo grupo.

patyrossini@gmail.com

Rafael Cardoso Sampaio é professor da UFPr e bolsista de Pós-Doutorado no EME/UFMG (Fapemig).

cardososampaio@gmail.com

Regiane Lucas Garcêz é professora e doutora em Comunicação pela UFMG e pesquisadora do Grupo de Pesquisa em Mídia e Esfera Pública da UFMG.

regianelucasgarcez@gmail.com

\section{Referências}

ADAMS, B. E. "Reason-Giving In Deliberative Forums". Journal of Public Deliberation: Vol. 10: Iss. 2, Article 6, 2014

BÄCHTIGER, A et. al. (2010). Disentangling diversity in deliberative democracy: competing theories, their blind spots and complementarities. Journal of Political Philosophy, 18(1), 32-63

BENHABIB, S. The claims of culture: Equality and diversity in the global era. New Jersey: Princeton University Press, 2002.

BLACK, L. W. Deliberation, Storytelling, and Dialogic Moments: Deliberation, Storytelling, and Dialogic Moments. Communication Theory, v. 18, n. 1, p. 93-116, 2008.

BRAGA, J. L. A sociedade enfrenta sua mídia: dispositivos sociais de crítica midiática. São Paulo: Paulus, 2006.

BRUNDIDGE, J. Encountering "Difference" in the Contemporary Public Sphere: The Contribution of the Internet to the Heterogeneity of Political Discussion Networks. Journal of Communication, $v$. 60, n. 4, p. 680-700, 2010.

CHADWICK, A. The Hybrid Media System: Politics and Power. Oxford: Oxford University Press, 2013.

CHAMBERS, S. Measuring publicity's effect: Reconciling empirical research and normative theory. Acta Politica, v. 40, n. 2, p. 255-266, 2005. 
CHONG, D.; DRUCKMAN, J. N. A theory of framing and opinion formation in competitive elite environments. Journal of Communication, 57(1), 99-118, 2007.

CONOVER, P. J.; SEARING, D. D. Studying "Everyday Political Talk" in the Deliberative System. Acta Politica, v. 40, n. 3, p. 269-283, set. 2005.

GAMSON, W. A. Talking politics. Cambridge: Cambridge University Press, 1992.

GOODIN, R. E. Sequencing Deliberative Moments. Acta Politica, v. 40, n. 2, p. 182-196, jul. 2005.

HABERMAS, J. Political Communication in Media Society: Does Democracy Still Enjoy an Epistemic Dimension? The Impact of Normative Theory on Empirical Research. Communication Theory, v. 16, n. 4, p. 411-426, nov. 2006.

HONNETH, A. (2002). Grounding recognition: A rejoinder to critical questions. Inquiry: An interdisciplinary. Journal of Philosophy, 45(4), 499-520.

HUCKFELDT, R.; JOHNSON, P. E.; SPRAGUE, J. Political Disagreement: The Survival of Diverse Opinions within Communication Networks. Cambridge: Cambridge University Press, 2004.

JACOBS, L. R.; COOK, F. L.; CARPINI, M. X. D. Talking Together: Public Deliberation and Political Participation in America. Chicago: University Of Chicago Press, 2009.

KIM, J.; KIM, E. J. Theorizing dialogic deliberation: Everyday political talk as communicative action and dialogue. Communication Theory, v. 18, n. 1, p. 51-70, 2008.

KRIPPENDORFF, K. H. Content Analysis: An Introduction to Its Methodology. 2nd edition. Thousand Oaks, Calif: Sage Publications, 2003.

LADEN, A. S. Reasoning: A Social Picture. Oxford: Oxford University Press, 2014.

LIKERT, R. A technique for the measurement of attitudes. Archives of Psychology, v. 22 140, p. 55, 1932.

MAIA, R. Deliberation, The Media and Political Talk. New York: Hampton Press, 2012.

MANSBRIDGE, J. Everyday Talk in the Deliberative System. In: MACEDO, S. (Ed.). Deliberative Politics: Essays on Democracy and Disagreement. Oxford: Oxford University Press, 1999. p. 1-211.

MARQUES, Â. C. S.; MAIA, R. C. M. Everyday Conversation in the Deliberative Process: An Analysis of Communicative Exchanges in Discussion Groups and Their Contributions to Civic and Political Socialization. Journal of Communication, v. 60, n. 4, p. 611-635, dez. 2010.

MOY, P.; GASTIL, J. Predicting Deliberative Conversation: The Impact of Discussion Networks, Media Use, and Political Cognitions. Political Communication, v. 23, n. 4, p. 443-460, 2006.

MUTZ, D. C. Hearing the other side: deliberative versus participatory democracy. Cambridge; New York: Cambridge University Press, 2006.

NEUENDORF, K. A. The Content Analysis Guidebook. Thousand Oaks, Calif: SAGE Publications, 2002.

PARKINSON, J. Democratizing deliberative systems. In: PARKINSON, J.; MANSBRIDGE, J. (org.). Deliberative systems: Deliberative democracy at the large scale, 2012.

SNIDERMAN, P. M.; THERIAULT, S. M. The structure of political argument and the logic of issue framing. Studies in public opinion: Attitudes, non-attitudes, measurement error, and change, $p$. 133-65, 2004.

STASAVAGE, D. Polarization and publicity: rethinking the benefits of deliberative democracy. Journal of Politics, v. 69, n. 1, p. 59-72, 2007. 
STEINER, J., JARAMILLO, M. C., MAIA, R. C. M., MAMELI, S. Deliberation across deep divisions: Transformative moments. Cambridge: Cambridge University Press, 2016 (no prelo)

STEINER, J. et al. Deliberative politics in action: crossnational study of parliamentary debates. Cambridge: Cambridge University Press, 2004.

STEINER, J. The Foundations of Deliberative Democracy. Cambridge: Cambridge University Press, 2012.

WALSH, K. C. Talking about Politics: Informal Groups and Social Identity in American Life. 1 edition ed. Chicago: University of Chicago Press, 2003.

WARREN, M. E. What should and should not be said: Deliberating sensitive issues. Journal of social philosophy, v. 37, n. 2, p. 163-181, 2006.

WRIGHT, S. From "Third Place" to "Third Space": Everyday Political Talk in Non-Political Online Spaces. Javnost - The Public, v. 19, n. 3, 2012.

ZHANG, W.; CHANG, L. Perceived Speech Conditions and Disagreement of Everyday Talk: A Proceduralist Perspective of Citizen Deliberation. Communication Theory, v. 24, n. 2, p. 124-145, 2014. 